\title{
El valor de la ciudad como fuente documental en las Cantigas Historiadas de Alfonso X el Sabio: el caso de Foggia
}

\author{
Laura MOLINA LÓPEZ \\ Departamento de Historia del Arte I (Medieval) \\ Universidad Complutense de Madrid \\ laura.molina.lopez@gmail.com
}

Recibido: 15 de abril de 2011

Aceptado: 29 de abril de 2011

\section{Resumen}

En este artículo se analiza la importancia del texto y la miniatura de las Cantigas de Santa María de Alfonso X el Sabio como fuente para el conocimiento de la ciudad. En concreto, centramos nuestra atención en la aparición de la ciudad de Foggia en la Cantiga CXXXVI del códice RBME, Ms. T.I.1., importante por transmitirnos una valiosa información tanto de la relación de la monarquía castellana del siglo XIII con esta ciudad, como de las distintas partes y elementos que componían su paisaje urbano.

Palabras clave: Foggia, cantigas, emperador, palacio, calle.

Title: The value of the city as documentary source in the Cantigas Historiadas of Alfonso X the Wise: Foggia's case

Abstract

This article analyzes the importance of the text and the miniatures of the Cantigas de Santa María of Alfonso X the Wise the city as a documentary source. Specifically we focus our attention on the representation of the city of Foggia in the poem CXXXVI of the codex RBME, Ms. T.I.1., giving an interesting information about the relationship between Castilian monarchy and that city, as well as the different parts that did compose its urban landscape.

Keywords: Foggia, cantigas, emperor, palace, street.

\section{Índice}

1. Introducción

2. "En terra de Pulla en hūa vila que chamā Foja"

2.1. La iglesia y la imagen de la Virgen con el Niño

2.2. El Rey y su palacio

2.3. Las calles de la ciudad

3. Conclusiones 


\section{Introducción}

Las denominadas Cantigas Historiadas se encuentran englobadas en la producción de distintos códices dentro del scriptorium alfonsí, siendo los volúmenes correspondientes el Ms. T.I.1 de la Biblioteca de El Escorial y el Ms. B.R.20 de la Biblioteca Nazionale Centrale di Firenze.

En estos manuscritos se produce una exaltación de la ciudad, tanto en el texto como en las miniaturas que lo ilustran, como una fuente documental que permite reforzar la veracidad del relato. Esto nos lleva a valorar el carácter científico que el Rey Sabio quería aplicar a su obra, revelando, como lo haría un investigador del siglo XXI, las fuentes de las que se había servido para la realización de la misma (Filgueira Valverde 1979: 44; Chico Picaza: en prensa).

El amplio repertorio de ciudades incluidas en las Cantigas nos traslada, no sólo a distintos lugares de la Península, sino a diversas regiones de Francia, Italia e, incluso, a África ${ }^{1}$. En relación con el contenido de la presente publicación, es necesario destacar el papel que desempeñan en estos códices las ciudades italianas, en cuya representación, sea a nivel textual, sea en el ámbito de la ilustración, se ha empleado un minucioso detallismo ${ }^{2}$.

Para el artículo que nos ocupa, centraremos nuestra atención en la aparición de la ciudad de Foggia, en la actual región de Puglia (Italia), en la Cantiga CXXXVI del Códice Rico de El Escorial (Ms. T.I.1), analizando detalladamente los elementos empleados para la emulación de este centro urbano, así como la carga simbólica que ésta supone dentro de la política europea de Alfonso X.

\section{2. "En terra de Pulla en hūa vila que chamā Foja"}

El texto ${ }^{3}$ recogido en la Cantiga CXXXVI (figura 1) del Códice Rico nos ofrece la historia de una mujer de procedencia alemana que se encuentra jugando una partida de dados junto a una iglesia en la villa de Foggia. Por ir perdiendo en el juego, monta en cólera e intenta agredir, arrojándole una piedra, a la imagen de la Virgen con el Niño,

\footnotetext{
${ }^{1}$ Para una relación completa de las ciudades concretas y de las regiones representadas en el Códice Rico de El Escorial (Ms. T.I.1), vid. Chico Picaza (1987: 238-240).

${ }^{2}$ La mayor parte de los relatos ambientados se aglutinan en el Códice de Florencia (Ms. B.R.20). En los distintos poemas se cita la ciudad, llegando en ocasiones a mencionar incluso el edificio en que se producen los acontecimientos. Así encontramos alusiones a San Juan de Letrán (Roma), Santa María Maggiore (Roma) o la Catedral de Siena, por mencionar algunos ejemplos (vid. Molina López: en prensa).

3 Se considera que la fuente de inspiración de este relato es de procedencia alemana, apuntándose en repetidas ocasiones a la relación con los Diálogos de Milagros de Cesario de Heisterbach (vid. Filgueira Valverde 1979: 211). De entre estos relatos de Cesario de Heisterbach, podríamos poner en relación con la Cantiga el Capítulo 44 de la Séptima Distinción, en el cual nos habla de dos jugadores, uno de los cuales no tenía suerte y, dando rienda suelta a su furor, comenzó a blasfemar contra Dios, pero su compañero le acusó de no saber blasfemar, y cuando empezó a blasfemar contra la Virgen, cayó fulminado por intervención de Cristo sobre la mesa en la que estaba jugando (vid. Heisterbach 1998: 605).
} 
MOLINA LÓPEZ, Laura (2011): "El valor de la ciudad como fuente documental en las Cantigas Historiadas de Alfonso X el Sabio: el caso de Foggia " [en línea]. En: Ángulo Recto. Revista de estudios sobre la ciudad como espacio plural, vol. 3, núm. 1, pp. 53-62. En: http://www.ucm.es/info/angulo/volumen/Volumen03-1/articulos03.htm. ISSN: 1989-4015 http://dx.doi.org/10.5209/rev_ANRE.2011.v3.n1.1951]

que gozaba de una gran devoción entre la población y la realeza de la ciudad. Fueron los propios asistentes a la escena los que llevaron a la mujer ante el rey, quien se ocuparía de la imposición del correspondiente castigo.

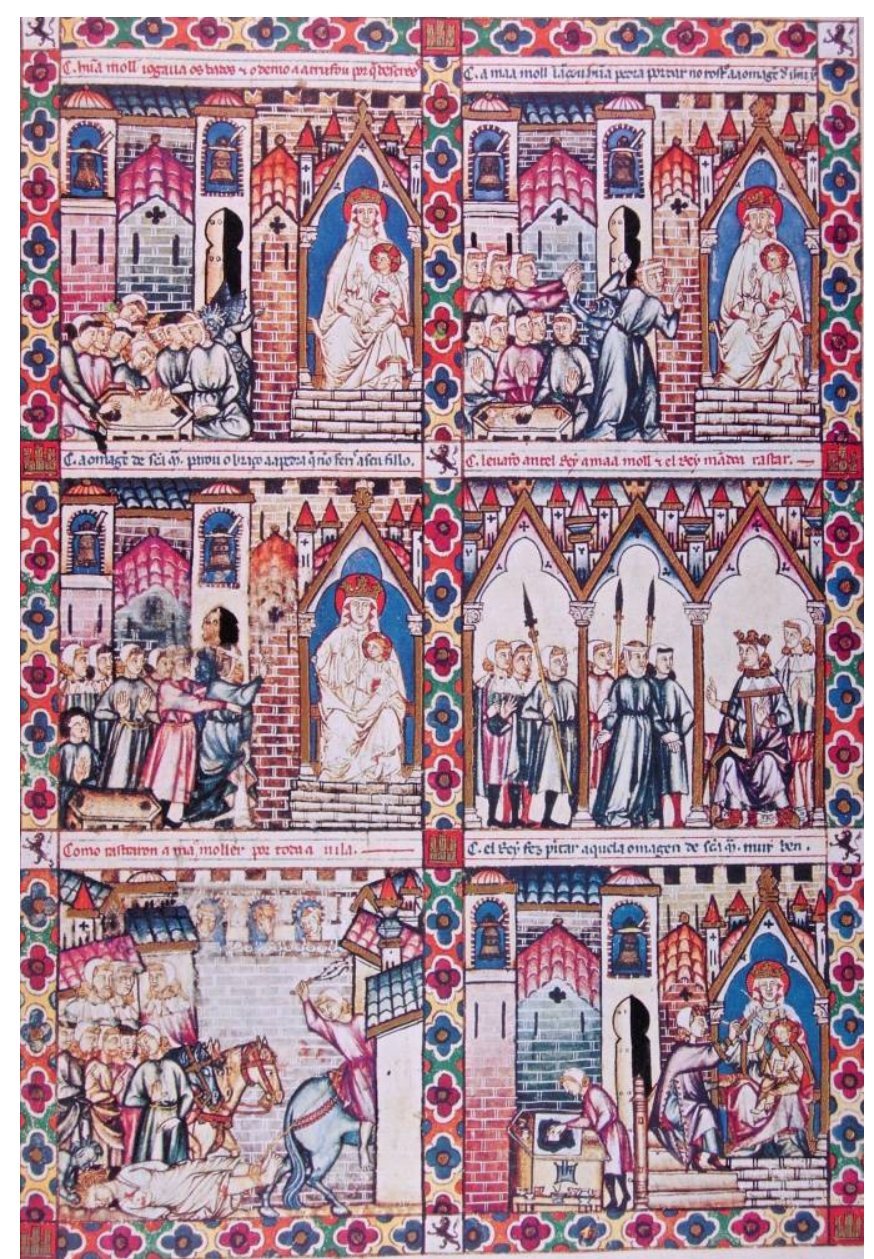

Figura 1. Códice Rico de El Escorial (Ms. T.I.1), Cantiga CXXXVI, fol. 192r.

Podemos apreciar cómo en la elaboración de esta cantiga, tanto a nivel textual como gráfico ${ }^{4}$, han sido introducidos, con gran minuciosidad y detallismo, distintos elementos para representar, con gran realismo, la ciudad de Foggia, que serán analizados a lo largo de los siguientes apartados y que ponen de relieve los lazos políticos y diplomáticos que ligaban a la monarquía castellana con esta ciudad.

Desgraciadamente, los edificios asociados a esta cantiga no se conservan o se encuentran muy reformados debido a la destrucción ocasionada en la ciudad por un terremoto que tuvo lugar en el siglo XVIII. Sin embargo, gracias a una visión panorámica de la ciudad de Foggia que se conserva en la Biblioteca Angélica de Roma, podemos

\footnotetext{
${ }^{4}$ Para mayor información sobre la estrecha relación que existe entre el texto y las imágenes en el Códice Rico de El Escorial, vid. Chico Picaza (1986).
} 
recrear el conjunto urbano tal y como se encontraba en el siglo XVI (figura 2).

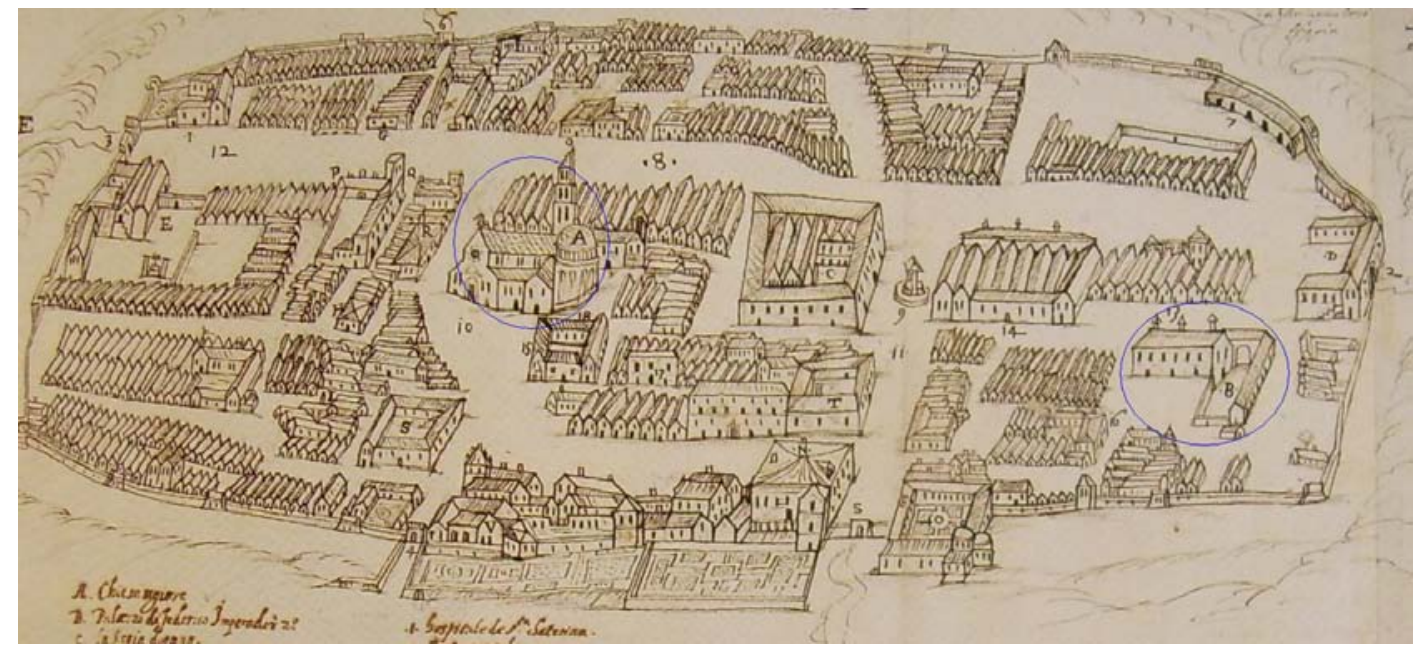

Fuente: Romanini (1995: 269)

Figura 2. Vista de la ciudad de Foggia (detalle), siglo XVI, Biblioteca Angelica de Roma, 1214, c.40r.

\subsection{La iglesia y la imagen de la Virgen con el Niño}

Esto na villa de Foja foi ant' un' egregia

ú estavu hūa omage da que sempre seja

bēeita, feita de mármor, de mui gran sobeja

beldade, en que as gentes avían fiança. (vv. 15-18)

El origen de la ciudad de Foggia, según la tradición religiosa, se encuentra ligado al hallazgo de un antiguo icono en el año 1062. Se trata de la Madonna Iconavetere o Madonna dei Sette Veli, una témpera sobre tabla en la cual se representa a la Virgen con el Niño, datada entre los siglos XI y XII, y que es objeto de gran veneración en la ciudad (Romanini 1995: 268-271). Observando las miniaturas $1,2,3$ y 6 del folio 192r. del Códice Rico, nos encontramos con una imagen de la Virgen sedente, con el Niño en su regazo, sobre un fondo azul y con numerosos detalles trabajados en oro -como la corona o el trono- que bien podría identificarse con la imagen de la Iconavetere o Madonna dei Sette Veli (Molina López: en prensa). A pesar de que el texto nos hable de una imagen realizada en mármol, por su tipología, así como por su organización iconográfica, mantenemos que se trata de un icono pintado sobre tabla, y no de un grupo escultórico, reforzándose esta idea gracias a la escena representada en la miniatura 6 (figura 3), en la que aparece un pintor con los pinceles y pigmentos dispuesto a restaurar la imagen tras la agresión sufrida por parte de la mujer. 


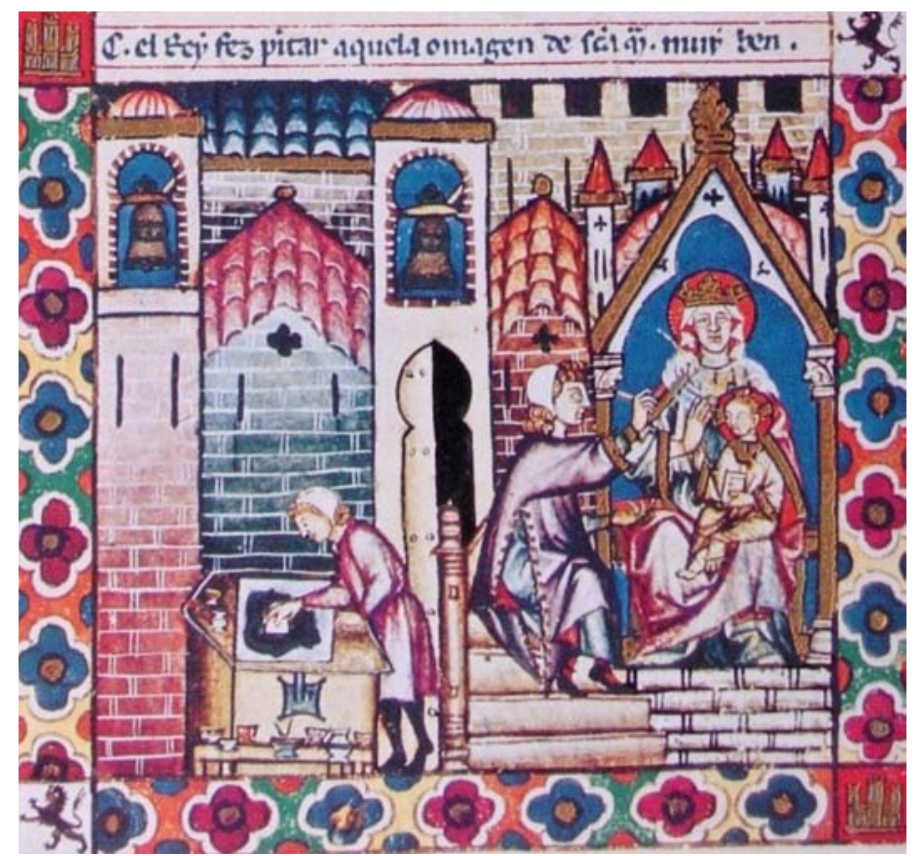

Figura 3. Códice Rico de El Escorial (Ms. T.I.1), Cantiga CXXXVI, fol. 192r., caja 6.

Del mismo modo, encontramos en el poema -"foi ant' un' egregia"- la alusión a una iglesia (figura 4) en la cual se encontraría esta imagen. Bien podría tratarse de la Iglesia de Santa Maria Assunta in Cielo di Foggia, actual catedral de la ciudad (su ubicación se señala en la figura 2, correspondiendo a la letra A) y que gozó de gran importancia durante el siglo XIII por haber sido elevada a la condición de capilla palatina por el emperador Federico II (Villani 1984: 125). Su vinculación a la realeza fue tal que varios monarcas destacados la eligieron para depositar en ella sus restos tras su muerte. Por un lado, Federico II depositó su corazón y sus vísceras en una urna que se ubicó en la portada principal del templo ${ }^{5}$, mientras que Carlos de Anjou eligió esta catedral para guardar parte de sus vísceras ${ }^{6}$.

\footnotetext{
5 "Il cadavere di Federico II fu intanto trasportato in Foggia e venne imbalsamato, giusta l'usanza dei tempi; nè è a dire con quanta pompa furono celebrati i suoi funerali. II cuore e i visceri del re furono custoditi in un'urna, e questa fu collocata sopra un arco sorretto da quattro colonne di verde antico in cima della porta maggiore della chiesa; il quale monumento andò disperso pel tremuoto del 1731" (Villani 1894: 49-51).

6 “[...] ivi [Foggia] morì [Carlo d'Angiò] nel 7 di gennaio 1284. Aveva già ordinato egli stesso che il suo cuore, chiuso in un'urna, venisse deposto nella chiesa palatina dei suoi maggiori in Francia, il corpo in Napoli, e le altre viscere nella chiesa di Foggia, a cui donò molte reliquie cesellate in argento con le parole: ex dono Reg. Caruli I Adegavensis" (Villani 1894: 77-78).
} 


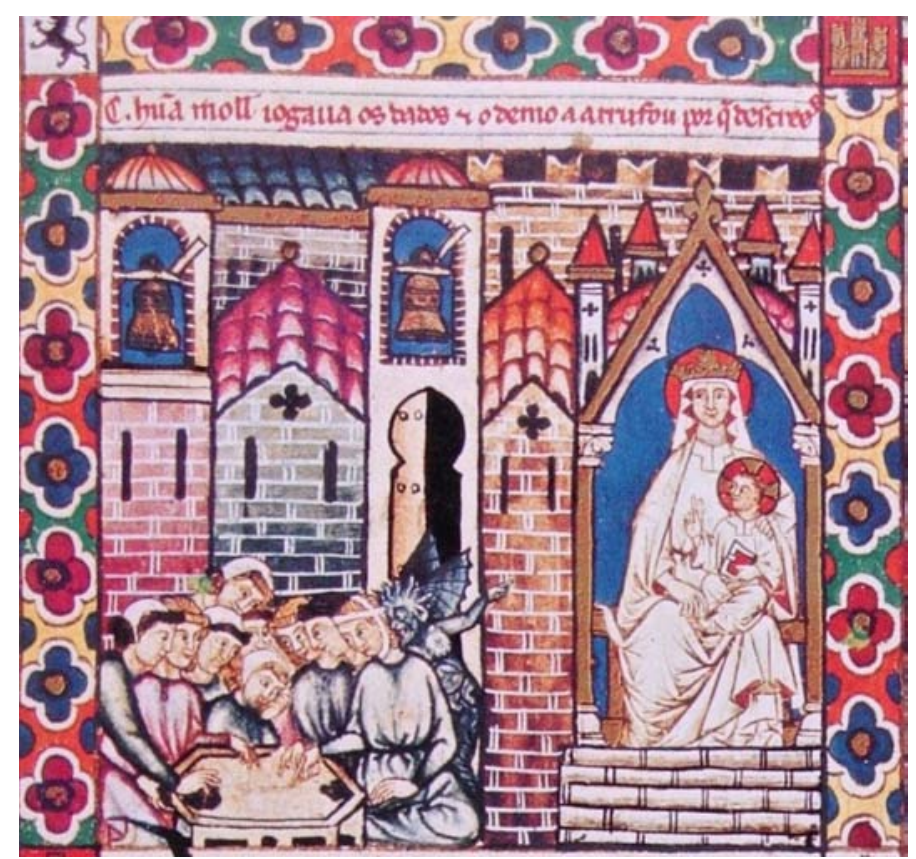

Figura 4. Códice Rico de El Escorial (Ms. T.I.1), Cantiga CXXXVI, fol. 192r., caja 1.

\subsection{El Rey y su palacio}

En essa vila, segund' aprix en verdade,

Fillo do Emperador ý era Rey Corrade (vv. 20-21)

Durante el reinado de Fernando III el Santo, siendo todavía Alfonso $X$ infante, la monarquía castellana ya había establecido relaciones con la ciudad de Foggia. Fue precisamente el infante don Fadrique, hijo de Fernando III y hermano menor de Alfonso $X$, el primero en tomar contacto con la sede imperial del Regnum Italiae ${ }^{7}$ de Federico II en el año $1240^{8}$, convirtiéndose en miembro de la corte del emperador, conocido como Stupor Mundi, hasta el año 1245 (vid. Molina López 2010). El objetivo perseguido por don Fadrique era el de

\footnotetext{
${ }^{7}$ Desde el momento de la coronación de Federico II en Roma el 22 de noviembre de 1220, hasta su muerte el 13 de diciembre de 1250 en Castel Fiorentino, pueden distinguirse dos etapas bien definidas por el traslado del centro de poder del Imperio. La primera abarcaría desde noviembre de 1220 hasta mayo de 1235, y se caracterizaría por la actividad del emperador en territorio siciliano (Regnum Siciliae); mientras que en el período comprendido entre el 16 de mayo de 1235 y la muerte de Federico II en el año 1250, el escenario de los acontecimientos se trasladó al ámbito peninsular (Regnum Italiae). El centro neurálgico del imperio se puede situar durante el período del Regnum Italiae en la ciudad de Foggia, que acumula el mayor número de estancias (siendo también las más prolongadas) de la corte del emperador con motivo de la celebración de festividades religiosas (vid. Brühl 1994: 34-47).

${ }^{8}$ En la Ryccardi de Sancto Germano Notarii Chronica (éd. de Georgius Henricus Pertz, en Scriptorum Rerum Germanicorum, vol. 54, 1864, p. 143), se recoge la información de la siguiente manera: "Eodem mense [abril de 1240] filius regis Castelle ad imperatore aput Fogiam venit".
} 
MOLINA LÓPEZ, Laura (2011): "El valor de la ciudad como fuente documental en las Cantigas Historiadas de Alfonso X el Sabio: el caso de Foggia " [en línea]. En: Ángulo Recto. Revista de estudios sobre la ciudad como espacio plural, vol. 3, núm. 1, pp. 53-62. En: http://www.ucm.es/info/angulo/volumen/Volumen03-1/articulos03.htm. ISSN: 1989-4015 http://dx.doi.org/10.5209/rev_ANRE.2011.v3.n1.1951

obtener la herencia imperial que le correspondía por herencia materna9.

En el año 1256 será el turno de Alfonso X para reclamar el legado de doña Beatriz de Suabia. La oportunidad le llegará de manos de unos embajadores de la ciudad de Pisa $^{10}$ que, encabezados por Bandino de Lancia, le propondrán la candidatura a la corona imperial. Una de las razones a las cuales se apelaba para justificar la elección del rey castellano como heredero al trono del Sacro Imperio era la existencia de los lazos de sangre que unían al rey Sabio con los Staufen ${ }^{11}$. Tras la muerte Conrado IV $^{12}$ en 1254, la sucesión correspondería a Conradino quien, debido a su corta edad, no podía ejercer el poder. De este modo, el Staufen vivo con más posibilidades de acceder a la dignidad imperial era el Alfonso X (González Jiménez 2004: 111).

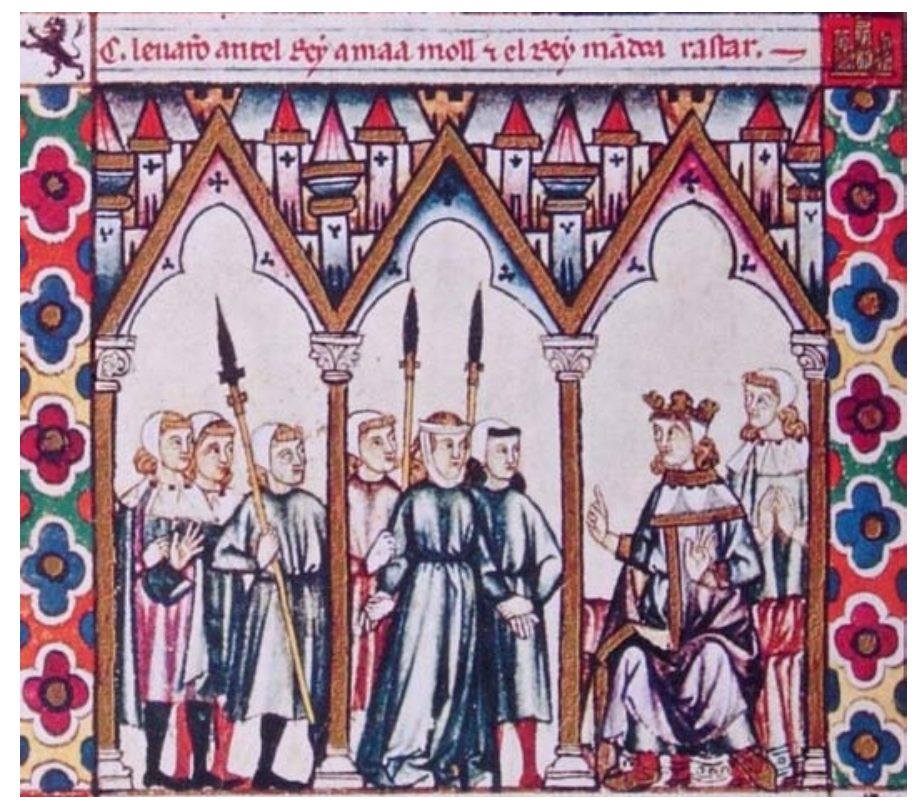

Figura 5. Códice Rico de El Escorial (Ms. T.I.1), Cantiga CXXXVI, fol. 192r., caja 4.

\footnotetext{
${ }^{9}$ Es obligado, para una mejor comprensión de esta situación, recordar el matrimonio de Fernando III el Santo, rey de Castilla y heredero del reino de León, con Beatriz, hija de Felipe, duque de Suabia y rey de Alemania.

${ }^{10}$ El testimonio de dichas embajadas se encuentra en cuatro documentos conservados en el Archivio di Stato di Pisa. Todos ellos pertenecen al fondo "Diplomatico Atti Pubblici"; tres de ellos datan del 18 de marzo de 1256 y han sido catalogados bajo la nomenclatura 1256 marzo 18, ind. XIV, Soria di Spagna, mientras que el cuarto de ellos recoge los privilegios comerciales otorgados a la ciudad de Pisa, y ha sido recogido como 1256 aprile 16, ind. XIV, Soria di Spagna.

${ }^{11}$ Según las palabras pronunciadas por el embajador pisano, Alfonso era "natum de progenie domus ducum Suevie ad quam de privilegio principum et de concessione romane ecclesie pontificum imperium iuste et digne dignoscitur pertinere" (Tronci 1967: 22 y ss.). Documento original en el Archivio di Stato di Pisa: 1256 marzo 18 ind. XIV, Soria di Spagna.

${ }_{12}$ Hijo de Federico II y primo de Alfonso X, que aparece representado en las miniaturas de la Cantiga CXXXVI del Códice Rico de El Escorial (Ms. T.I.1, fols. 191v.-192r.), cuyo estudio nos ocupa a lo largo del presente artículo. La inclusión de Conrado IV, tanto en el texto, mediante la expresión "aprix en verdade", como en la imagen, responde a la intención de mostrar un hecho que es contemporáneo al reinado de Alfonso X (vid. Filgueira Valverde 1979: 211).
} 
A la aparición de la figura de Conrado IV (figura 5) podríamos vincular también la emulación, en cierto modo indirecta, de la residencia palaciega en la cual se encontraría cuando la población llevó ante él a la mujer que agredió a la imagen de la Virgen con el Niño. Detengámonos en estos años en los que el Stupor Mundi ostentaba el poder imperial.

Durante los primeros años del reinado de Federico II, la arquitectura de carácter militar se convirtió en el vehículo de expresión de la voluntad del emperador. A este período se remonta la construcción del palatium de Foggia (su ubicación se señala en la figura 2, correspondiéndose con la letra B), que, por deseo del soberano, albergó obras de valor y estaba decorado con mármoles y esculturas, hecho que, una vez más, pone en evidencia el carácter excepcional del que gozaron esta ciudad y las construcciones que en ella se llevaron a cabo. Desgraciadamente, hoy se conserva solamente el arco de acceso del palatium, en cuya lastra epigráfica han permanecido a lo largo de los siglos los nombres del emperador Federico II y de Bartolomeo di Foggia, el arquitecto que se ocupó de la construcción de la residencia imperial (vid. Resta 1995).

\subsection{Las calles de la ciudad}

Quand' aquesta foi al Re contada, logo foi por seu mandado a moller fillada, des í per toda-las rúas da vila rastrada; desta guisa a ssa Madre quis Deus dar vingança. (vv. 35-38)

Por último, el poema hace una mención explícita de las calles de la ciudad de Foggia. Es interesante destacar cómo éstas cobran importancia, no sólo como parte de la estructura urbana, sino como escenario en el que transcurre la vida de los ciudadanos y en el cual se lleva a cabo la aplicación del castigo, que servirá de ejemplo al resto de los habitantes (figura 6 ).

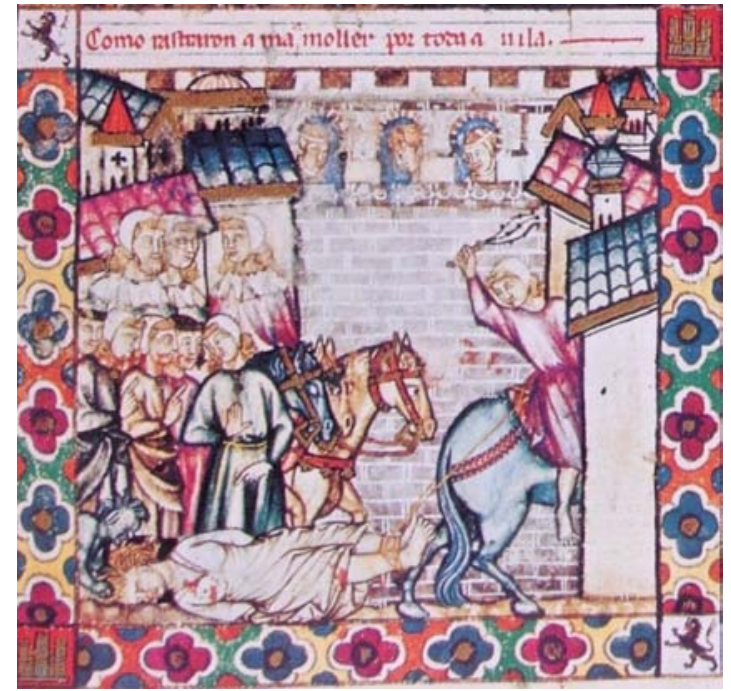

Figura 6. Códice Rico de El Escorial (Ms. T.I.1), Cantiga CXXXVI, fol. 192r., caja 5. 
Se presenta ante nuestros ojos un paisaje urbano intramuros compuesto por dos volúmenes arquitectónicos laterales, y cerrado, en la parte posterior, por la introducción de un lienzo de muro con ventanas a las que se asoman algunos personajes femeninos para presenciar la escena. Esta estructura ha sido puesta en relación con la de una plaza cerrada (Chico Picaza 1987: 270), mostrándonos así la función conmemorativa que este espacio desempeñaba dentro la ciudad como lugar tanto de celebraciones como de condenas, de las que los ciudadanos eran testigos y de las cuales debían tomar ejemplo.

\section{Conclusiones}

Tras el análisis conjunto del texto y las miniaturas de la Cantiga CXXXVI del Códice Rico, nos percatamos del especial cuidado que se ha puesto en la obtención de una representación veraz de la ciudad de Foggia. Podemos observar cómo han sido enumerados cada uno de los elementos arquitectónicos que eran indispensables en una ciudad medieval que ostentase el papel de capital imperial, siendo capaces, incluso, de individualizar cada uno de ellos con edificios conservados y perfectamente documentados.

Encontramos pues, una iglesia, identificada con la actual catedral; una imagen hacia la cual la población profesa una especial devoción, identificada con la Madonna dei Sette Veli; una alusión a las calles de la ciudad y una mención indirecta al palacio, asociada al palatium de Foggia, a través de la representación del hijo del Emperador. El deseo de especificar que éste no es otro que Conrado IV responde a la intención de circunscribir el relato a una cronología concreta, entre 1250 y 1254 , que se encuentra en estrecha relación con la política exterior de Alfonso $X$, coincidiendo con el punto de partida del denominado fecho del Imperio y con la reivindicación por parte del rey Sabio de un vínculo directo con la dinastía de los Staufen que reforzara su candidatura a la herencia de la corona imperial.

\section{Bibliografía}

BRÜHL, Carlrichard (1994): "L'itinerario dell'imperatore: 1220-1250", en Pierre Toubert y Agostino Paravicini Bagliani (a cura di), Federico II, vol. 3, pp. 34-47. Palermo: Sellerio.

CHICO PICAZA, M. Victoria (1986): "La relación texto-imagen en la miniatura del Códice Rico de las Cantigas de Santa María", en Reales Sitios, XXIII, pp. 65-72.

- (1987): Composición Pictórica en el Códice Rico de las Cantigas de Santa María, tomo 1. Madrid: Universidad Complutense de Madrid. 
MOLINA LÓPEZ, Laura (2011): "El valor de la ciudad como fuente documental en las Cantigas Historiadas de Alfonso X el Sabio: el caso de Foggia " [en línea]. En: Ángulo Recto. Revista de estudios sobre la ciudad como espacio plural, vol. 3, núm. 1, pp. 53-62. En: http://www.ucm.es/info/angulo/volumen/Volumen03-1/articulos03.htm. ISSN: 1989-4015

http://dx.doi.org/10.5209/rev_ANRE.2011.v3.n1.1951

- (en prensa): "La visión de 'sones' y 'trobas'. Composición pictórica y estilo en la miniatura del Códice Rico", en Edición Facsímil de las Cantigas de Santa María.

FILGUEIRA VALVERDE, José (1979): "El texto de las Cantigas de Santa María", en El Códice Rico de las Cantigas de Alfonso X el sabio. Ms. T.I.1. Volumen complementario de la Edición Facsímil del ms. T.I.1 de la Biblioteca de El Escorial, pp. 23-248. Madrid: Edilán.

GONZÁLEZ JIMÉNEZ, Manuel (2004): Alfonso X el Sabio. Barcelona: Ariel.

HEISTERBACH, Cesario de (1998): Diálogo de Milagros, vol. II. Introducción, versión y notas de Zacarías Prieto Hernández. Zamora: Ediciones Monte Casino.

MOLINA LÓPEZ, Laura (2010): "La entrada de un modelo arquitectónico federiciano en el Reino de Castilla: la Torre de don Fadrique", en Nuevas Investigaciones en Historia del Arte. Anales de Historia del Arte, vol. Extra 3, pp. 185-200.

- (en prensa): "Viaje a Italia a través de las Cantigas Historiadas de Alfonso X el Sabio", en Anales de Historia del Arte, vol. Extraordinario.

RESTA, Fulvio (1995): "Il portale del Palazzo di Foggia", en Maria Stella Calò Mariani y Raffaella Cassano (a cura di), Federico II. Immagine e potere, pp. 235-237. Venezia: Marsilio.

ROMANINI, Angiola Maria (dir.) (1995): Enciclopedia dell'arte medievale, vol. VI, pp. 268-271. Milán: Istituto della Enciclopedia Italiana.

TRONCI, Paolo (1967): "Memorie Istoriche della Città di Pisa", en Historiae Urbium et Regionum Italiae Rariores, num. XLIII. (Ristampa foto meccanica; originale dell'anno MDCLXXXI). Bologna: Forni Editore.

VILLANI, Ferdinando (1894): Foggia al tempo degli Hohenstaufen e degli angioini. Con Prefazione ed Appendice di Carlo Villani. Trani: V. Vecchi. 